\title{
Ozônio e ultra-som: processos alternativos para o tratamento do café despolpado
}

\author{
Ozone and ultrasound: alternative processes in the treatment of fermented coffee
}

\author{
Luiz Carlos do NASCIMENTO ${ }^{1,2 *}$, Luiz Carlos de Oliveira LIMA³, Roberta Hilsdorf PICOLLI ${ }^{3}$, \\ João Evangelista FIORINI², Stella Maris da Silveira DUARTE¹, José Maurício Schneedorf Ferreira da SILVA, \\ Nelma de Mello Silva OLIVEIRA ${ }^{2}$, Sandra Maria de Oliveira Morais VEIGA ${ }^{1}$
}

\section{Resumo}

Há um crescente interesse em tecnologias que melhorem a qualidade dos alimentos, bem como o aspecto segurança alimentar. Após a água, o café é a bebida mais consumida no planeta, existindo uma demanda crescente por tipos especiais em alguns países importadores, como o café despolpado. Este tipo é obtido pela remoção da mucilagem, ao se submeter o café à fermentação, cujo processo varia com o clima e a microbiota associada, entre outros fatores, podendo levar ao detrimento da qualidade do produto e da saúde do consumidor. Assim, faz-se necessário investigar novas tecnologias que possam auxiliar na obtenção de produtos com melhor padronização, qualidade e que ofereçam maior segurança alimentar. O ozônio e o ultra-som são tecnologias usadas em diversas áreas, com grande flexibilidade e resultados promissores na obtenção e no tratamento de uma infinidade de alimentos. São conhecidas as potentes características oxidantes e microbicidas de ambos, mas seus mecanismos ainda não são bem esclarecidos quando utilizados em tecidos vivos. Seus efeitos sobre os vários parâmetros de qualidade devem ser estudados, compreendidos e ajustados, antes de serem utilizados em larga escala na indústria. No presente trabalho, foi aplicado o ozônio ou o ultra-som como tratamentos prévios à fermentação do café, demonstrando sua eficácia na melhoria da segurança alimentar do café despolpado, sem alteração perceptível da qualidade da bebida.

Palavras-chave: café despolpado; ozônio; ultra-som; qualidade; sensorial.

\begin{abstract}
There is a growing interest in technologies that improve food quality, as well as food safety aspects. After water, coffee is the most consumed beverage in the planet, with a rising demand for special types, such as fermented coffee, in some importing countries. This type of coffee is obtained by removing the mucilage, submitting the coffee to fermentation, a process that varies with the climate and the associated natural micro-organisms, among other factors, and that can lead to detrimental effects to the quality of the product and to the health of consumers. Thus, it is necessary to investigate new technologies that can help obtain better standardized products, of higher quality and that offer greater food safety. Ozone and ultrasound are technologies used in various areas, with great flexibility and promising results in the production and treatment of an infinity of food products. The potent oxidant and antimicrobial characteristics of both are well-known, however, their mechanisms are still not clearly understood when used in live tissues. Their effects on the various quality parameters must be studied, understood and adjusted, before widespread use in the food industry. In the present paper, ozone or ultrasound were applied as pre-treatments before coffee fermentation, demonstrating their efficacy in improving food safety of the fermented coffee, without perceptible changes in the quality of the beverage.
\end{abstract}

Keywords: fermented coffee; ozone; ultrasound; quality; sensorial.

\section{Introdução}

Cada vez mais se intensifica a demanda por produtos com qualidade diferenciada. O café, por ser um produto consumido mundialmente, tem sua produção vista com atenção e regulamentada por órgãos certificadores, que buscam qualidade não só do produto em si, mas também de onde, como e por quem é produzido. Sabe-se que o café, para ter qualidade assegurada, depende de vários fatores que se estendem desde o local de plantio até o seu consumo.

Desse modo, o café de qualidade depende de muitos fatores, tais como: boas práticas agrícolas, de processamento, de benefi- ciamento, de armazenamento, de transporte, de industrialização e de consumo.

O café despolpado é um tipo de café especial, apreciado em alguns países do primeiro mundo, que se certificam da qualidade do mesmo para o adquirirem, impondo limites de tolerância cada vez mais restritos. Assim, o café deve ser homogêneo, com características bem definidas de sabor, corpo, doçura, acidez, entre outras, e principalmente deve ser seguro em relação ao seu consumo.

O café não é considerado um alimento nutritivo, mas devese observar que depois da água é o líquido mais ingerido no pla-

Recebido para publicação em 4/7/2006

Aceito para publicação em 25/2/2008 (001783)

${ }^{1}$ Universidade Federal de Alfenas - UNIFAL, Rua Ana Neri, 340, Centro, CEP 37130-000, Alfenas - MG, Brasil, E-mail: luizcnascimento@gmail.com

2 Universidade José do Rosário Vellano - UNIFENAS, Alfenas - MG, Brasil

${ }^{3}$ Universidade Federal de Lavras - UFLA, Lavras - MG, Brasil

${ }^{*}$ A quem a correspondência deve ser enviada 
neta, e por isso deve haver a preocupação com a sua qualidade. Para tanto, são necessários conhecimentos indispensáveis que venham garantir a sua produção de forma adequada, visando à segurança alimentar.

Existe uma grande preocupação com microrganismos que afetam os frutos do café, cujos danos se expressam no aspecto, na qualidade, no sabor, na segurança alimentar e no rendimento do produto (EMBRAPA, 2004), sendo necessária a busca por processamentos que eliminem ou atenuem estes danos. Com esta preocupação em relação aos alimentos, alguns autores citam determinadas aplicações do ozônio no controle de fungos na pós-colheita de certos vegetais consumidos pelo homem (PALOU et al., 2002; SUSLOW, 2004). Outros, utilizando ozônio, obtiveram redução de toxinas e contagem de fungos em alimentos (KIM; YOUSEF; DAVE, 1999; VEIGA, 2003) ou em suspensões (BEUCHAT, 1999).

Vários autores citam a questão da ocratoxina (OTA), principal micotoxina encontrada no café, produzida por espécies de Aspergillus e Penicillium (BATISTA et al., 2003, SUÁREZ-QUIROZ et al., 2004), enfatizando a necessidade de medidas preventivas para evitar a contaminação e ou desenvolvimento de fungos. A OTA não é destruída durante o processo de torração e é totalmente extraída no preparo da bebida do café (AHMAD; THARAPPAN; BONGIRWAR, 2002).

No processo de obtenção do café despolpado (via úmida), o mesmo passa por uma etapa de fermentação (dependente de condições climáticas, tipos de microrganismos, tempo, entre outros), na qual a microbiota se desenvolve, acidificando o sistema e degradando a mucilagem dos grãos de café. Ao retirá-la, há uma redução no tempo de secagem do café com conseqüente redução da deterioração e contaminação microbiana, evitando prejuízos aos produtores e à saúde dos consumidores.

Além dos microrganismos responsáveis pela fermentação do café, existem aqueles que podem causar doenças ou produzir toxinas potentes, justificando a utilização de processos de obtenção do café que evitem ou minimizem estes agravos.

O ozônio e o ultra-som são empregados em tecnologias modernas, reconhecidas por serem eficazes na obtenção de vários alimentos, com redução ou mesmo eliminação de microrganismos, além de melhorarem as condições de processamento de muitos produtos, atendendo às novas tendências de mercado. Como tecnologias emergentes, há a necessidade de estudos aprofundados para seu emprego, buscando melhor padronização e quantificação.

O Brasil, como líder mundial na produção e exportação de café, além de grande consumidor do produto, deve atender às exigências do mercado internacional por cafés de melhor qualidade, buscando e adotando novas tecnologias de produção.

Assim, foi objetivo deste trabalho avaliar o emprego do ozônio e do ultra-som em tratamentos prévios à fermentação, visando melhorar a padronização e a obtenção de café despolpado, bem como avaliar as amostras de café tratadas em relação aos seus aspectos microbiológicos, físico-químicos, químicos e sensoriais, para se certificar da viabilidade do emprego de tais tecnologias.

\section{Material e métodos}

Este trabalho foi desenvolvido no Laboratório de Biologia e Fisiologia de Microrganismos da Universidade José do Rosário Vellano (UNIFENAS), Alfenas-MG; no Laboratório de Produtos Vegetais I do Departamento de Ciência dos Alimentos da Universidade Federal de Lavras (UFLA), Lavras-MG e com a colaboração das empresas: White Martins Gases Industriais S/A e Ipanema Agrícola S/A, além da Universidade Federal de Alfenas (UNIFAL-MG).

\subsection{Material}

Café

As amostras de grãos de café tiveram como procedência a Fazenda Conquista, de propriedade da Ipanema Agrícola S/A, sediada em Alfenas-MG. Em cada experimento, foram utilizados aproximadamente $50 \mathrm{~kg}$ de amostras de café arábica, estádio cereja, cultivar Catuaí Amarela, colhidas, separadas e descascadas mecanicamente na própria fazenda. $\mathrm{O}$ transporte foi feito em frascos plásticos, com capacidade para $50 \mathrm{~L}$, lavados com água ozonizada. Para evitar a fermentação das amostras, estas foram levadas ao laboratório, distante aproximadamente $20 \mathrm{~km}$, onde foram processadas imediatamente.

\section{Água}

A água utilizada em todos os experimentos era proveniente da própria fazenda, a qual é captada no Lago de Furnas e armazenada em um grande tanque, sem nenhum tratamento. Essa mesma água é utilizada pelo produtor na lavagem e fermentação do café.

Para o transporte da água até o laboratório, foram utilizados frascos plásticos com capacidade para $50 \mathrm{~L}$, lavados com água ozonizada.

\subsection{Aparelhagem}

\section{Gerador de ozônio}

Para a produção de ozônio, foram utilizados um gerador de ozônio (Ozone, EAS 30-UV), um cilindro de oxigênio, válvulas redutoras de pressão, fluxômetros e manômetros, além de outros aparatos necessários e resistentes à ação do ozônio, fornecidos pela empresa White Martins Gases Industriais S/A.

$\mathrm{O}$ gerador tem a capacidade nominal de gerar $10,0 \mathrm{~g} / \mathrm{h}$ de ozônio, na proporção de $3 \% \mathrm{p} / \mathrm{p}$ da mistura de ozônio/ oxigênio, com pressão de entrada de oxigênio e vazão constantes (4,2 L/min a 1,0 kgf.cm ${ }^{-2}$ de pressão). Nos experimentos, foram utilizados $5,0 \mathrm{~L} / \mathrm{min}$ a $0,5 \mathrm{kgf} . \mathrm{cm}^{-2}$ de pressão, com produção de ozônio em torno de $6,88 \mathrm{~g} / \mathrm{h}$. Na saída do gerador foi adaptado um tubo de poliuretano (PolyFlow), ao qual foi acoplado um espargidor (difusor) em aço inox sinterizado, com a finalidade de produzir bolhas finas.

Para se certificar da produção e da concentração de ozônio, foram utilizadas amostras de água com volumes de $50 \mathrm{~L}$, em frascos plásticos, ozonizadas por 30 minutos. Após este período, 
alíquotas foram analisadas, estabelecendo-se, após a revisão dos trabalhos de Veiga (2003) e Oliveira (2005), uma concentração mínima de 3,5 mg. $\mathrm{L}^{-1}$ de ozônio dissolvido na água para serem iniciados os tratamentos dos grãos com este gás.

\section{Cuba ultra-sônica}

Durante os experimentos com emprego do ultra-som, foi utilizada uma cuba lavadora ultra-sônica, em aço inoxidável, marca Sercon, modelo USC 5080, com freqüência de 37 kHz e temperatura ambiente, cedida pela Universidade José do Rosário Vellano e White Martins Gases Industriais S/A.

\subsection{Determinação da concentração de ozônio}

Durante os experimentos, a concentração de ozônio foi verificada pelo método iodimétrico (APHA, 1992).

\subsection{Modelos experimentais}

Todas as amostras receberam números aleatórios de três algarismos, obtidos em uma tabela de números aleatórios (HAAHR, 2008).

\section{Processamento inicial}

Nos tratamentos, foram utilizados $8 \mathrm{~kg}$ de café para cada amostra e água até completar o volume de $10 \mathrm{~L}$. Com o intuito de se evitar variáveis, todos os tratamentos com ozônio e ultra-som foram realizados na cuba ultra-sônica, a qual possui volume de $10 \mathrm{~L}$.

Durante os tratamentos, em intervalos regulares, foram verificados o $\mathrm{pH}$ e a temperatura de cada sistema.

\section{Fermentação (controle)}

Amostras de café foram colocadas em recipientes plásticos com capacidade para $10 \mathrm{~L}$, em porções de $8 \mathrm{~kg}$, cobertas com água até completar o volume total, ficando em ambiente isolado do laboratório para que ocorresse fermentação. O tempo de fermentação foi estipulado em 24 horas (COFFEE TALK, 2002; HICKS, 2001).

Estas amostras, que passaram apenas pelo processo de fermentação, sem tratamento prévio, foram denominadas amostras controle.

Processamento com ozônio seguido de fermentação

As amostras de café foram colocadas na cuba ultra-sônica, cobertas com água até o volume de $10 \mathrm{~L}$ e, no fundo da cuba, foi colocado um difusor de ozônio, acoplado à extremidade de saída do gerador de ozônio, com a finalidade de produzir bolhas finas para facilitar a ação do gás. Em seguida, $\mathrm{O}$ gerador foi acionado pelo período de 60 minutos, com freqüente agitação da amostra, uma vez que a concentração de ozônio é maior quando próxima do difusor. Durante o experimento, alíquotas da água do sistema foram coletadas e analisadas quanto ao teor de ozônio.
Após o término do tratamento com ozônio, as amostras de café tratadas foram transferidas para frascos plásticos com capacidade de $10 \mathrm{~L}$, cobertas com água até o volume total e deixadas fermentando por 24 horas.

Processamento com ultra-som seguido de fermentação

Amostras de café foram colocadas na cuba ultra-sônica, em porções de $8 \mathrm{~kg}$, e cobertas com água até o volume de $10 \mathrm{~L}$. Em seguida, o ultra-som foi acionado por um período de 60 minutos, com freqüente agitação da amostra, uma vez que não é uniforme a ação do ultra-som em toda a cuba.

Após o tratamento com ultra-som, as amostras de café foram transferidas para frascos plásticos com capacidade de $10 \mathrm{~L}$, cobertas com água até completar o volume total e deixadas fermentando por 24 horas.

\section{Processamento final}

Após cada tratamento, as amostras de café foram lavadas por imersão em água e levadas para secar em peneiras, expostas ao sol na fazenda produtora, até atingir umidade aproximada de $12 \%$.

As amostras foram então beneficiadas, retirando-se o pergaminho, colocadas em embalagens plásticas e armazenadas em ambiente fresco e seco.

\subsection{Análises das amostras}

\section{Análises microbiológicas}

Foram realizadas análises de amostras de café e água, antes dos tratamentos, a fim de quantificar mesófilos, fungos filamentosos, leveduras e o número mais provável (NMP) de coliformes.

Para os testes microbiológicos, as amostras de café foram retiradas após os tratamentos e antes de serem levadas para a secagem.

Em frascos estéreis, com capacidade para $500 \mathrm{~mL}$, foram pesados $25 \mathrm{~g}$ de grãos de café e adicionados $225 \mathrm{~mL}$ de solução salina peptonada, sendo então homogeneizados em agitador mecânico orbital, tipo shaker, marca Tecnal, modelo TE140, a $120 \mathrm{rpm}$, por cinco minutos. Esta suspensão (diluição $10^{-1}$ ) e diluições decimais subseqüentes foram utilizadas para os seguintes experimentos: contagem global de microrganismos mesófilos, pela técnica do pour plate (SILVA; JUNQUEIRA; SILVEIRA, 2001); contagem de leveduras e fungos filamentosos, por semeadura em superfície; e Número Mais Provável (NMP) de coliformes e E. coli, pela técnica do substrato cromogênico (APHA, 1992; SILVA; JUNQUEIRA; SILVEIRA, 2001).

Análises de qualidade do café

Utilizando técnicas padronizadas, foram realizadas análises de sólidos solúveis totais (MAEZTU et al., 2001), acidez titulável e pH (AOAC, 1990), açúcares totais, redutores e não redutores (AOAC, 1990; NELSON, 1944), compostos fenólicos 
totais (AOAC, 1990; GOLDSTEIN; SWAIN, 1963), condutividade elétrica (LOEFFLER; TEKRONY; EGLI, 1988), lixiviação de potássio (PRETE, 1992), enzimas poligalacturonase (PG) (NELSON, 1944; PRESSEY; AVANTS, 1973), pectinametilesterase (RATNER; GOREN; MONSELINE, 1969), polifenoloxidase (PFO) (CARVALHO et al., 1994; DRAETTA; LIMA, 1976, PONTING; JOSLYNG, 1948).

As determinações de condutividade elétrica e de lixiviação de potássio foram realizadas nos grãos inteiros. As determinações de atividades enzimáticas (polifenoloxidase, pectinametilesterase e poligalacturonase), sólidos solúveis totais, acidez titulável, $\mathrm{pH}$, açúcares e compostos fenólicos totais foram realizadas com os grãos congelados em nitrogênio líquido, moídos em moinho tipo Croton Mod. TE-580, utilizando-se peneira de 30 mesh e mantidos em freezer a $-60^{\circ} \mathrm{C}$ até serem analisados.

\section{Análises sensoriais da bebida de café}

Nas análises sensoriais, as amostras foram preparadas com a metodologia adotada pela fazenda fornecedora dos grãos de café, conforme descrito a seguir.

Para o preparo da bebida, foram utilizados $120 \mathrm{~g}$ de café beneficado, livre de defeitos (catação), com torração americana feita em torrador de café marca Leogap - Probat, modelo TP4-G, por aproximadamente 7 a 8 minutos, a 110 e a $150{ }^{\circ} \mathrm{C}$ (temperatura inicial e temperatura final, respectivamente), sob agitação constante. Após a torra, o café foi moído em moedor de café marca Mecamau, modelo 1990, passando por moagem grossa.

Em cada xícara, foram transferidos $10 \mathrm{~g}$ de café moído, sobre o qual foram vertidos $100 \mathrm{~mL}$ de água quente (água mineral com $\mathrm{pH}$ de 5 a 7 e 90 a $96^{\circ} \mathrm{C}$ ), deixando em repouso para decantar e resfriar até a temperatura de $55^{\circ} \mathrm{C}$, para ser então provado. A mesa de prova consistiu de sete xícaras para cada amostra de café. Cada provador fez duas provas por xícara.

As amostras tratadas e a amostra controle foram avaliadas mediante análise sensorial e classificação da bebida, mediante prova de xícara por um painel de cinco classificadores de cafés especiais, utilizando tabela adotada pela Associação Brasileira de Cafés Especiais (ABCE) (Tabela 1), com modificações.

Nesta avaliação, foram adotados os parâmetros: bebida limpa, doçura, acidez, corpo, sabor, sabor remanescente (after taste), balanço e geral, atribuindo notas em escala crescente de aceitação de 0 a 8 para cada amostra. O valor final é dado pela soma de todos os atributos com um fator de correção próprio para cada tipo de café (dependente da cultivar, dos tipos de colheita, do processamento, etc.). Na utilização de amostras de frutos cereja de café arábica, colhidas, lavadas e descascadas mecanicamente, é atribuído o valor 36 como fator de correção. No caso dos cafés especiais, para serem certificados, necessitam obter nota mínima de 80 .
As notas dadas para cada atributo utilizado, segundo a ABCE (2003) são:

0) inaceitável;

2) pobre;

4) normal;

5) bom;

6) fino;

7) excelente; e

8) extraordinário.

Na avaliação da bebida, são considerados pontos positivos e negativos que podem ser notados pelos classificadores e contribuem para a nota.

Pontos positivos

- Xícara limpa: uniformidade, pureza, límpida, etc;

- Doçura: amadurecida, caramelo, mel, baunilha, etc;

- Acidez: viva, suave, sensível, brilho, prazerosa, cítrica, branda, firme, etc;

- Corpo: cremoso, redondo, denso, cheio, encorpado, aveludado, rico, etc;

- Sabor: caráter, intensidade, simples ou complexo, profundidade, doce, frutas, chocolate, baunilha, passas, amêndoas, nozes, floral, etc;

- Sabor remanescente: doce, durável, demorado, etc;

- Balanço: equilíbrio, harmonia, consistente, afinado, etc; e

- Geral: complexo, dimensão, uniformidade, riqueza, etc.

Pontos negativos

- Defeitos: rio, riada, dura, fenólico, acebolado, suado, fermentação, etc;

- Xícara limpa: suja, térreo, obscuro, eucalipto, etc;

- Doçura: imaturo, pouco desenvolvida, fechada, azeda, verde, etc;

- Acidez: azeda, magra, acética, agressiva, morto, dureza, picante, fraca, etc;

- Corpo: adstringente, áspero, aguado, ralo, arenoso, etc;

- Sabor: amargor ruim, couro, azedo, fumaça, sacaria, amendoim, batata, ervilhas, grama, esterco, vegetal, madeira, peixe, etc;

- Sabor remanescente: lento, amargo, severo, duro, sujo, desagradável, etc;

Tabela 1. Tabela adaptada para avaliação sensorial das amostras de café.

\begin{tabular}{|c|c|c|c|c|c|c|c|c|c|c|c|}
\hline \multirow[t]{2}{*}{ Amostra } & \multirow[t]{2}{*}{ Aspecto } & \multirow[t]{2}{*}{ Tipo bebida } & \multicolumn{8}{|c|}{ Bebida } & \multirow[t]{2}{*}{ Fator de correção } \\
\hline & & & Limpa & Doçura & Acidez & Corpo & Sabor & After taste & Balanço & Geral & \\
\hline
\end{tabular}

Fonte: ABCE, 2003 (modificada). 
- Balanço: choco, agressivo, inconsistente, etc; e

- Geral: simplista, chato, estranho, etc.

\subsection{Análise estatística}

O experimento foi conduzido em delineamento inteiramente casualizado, composto de três tratamentos (controle, ozônio + fermentação e ultra-som + fermentação), com três repetições. A unidade experimental constou de grãos de café descascados, na quantidade de $8 \mathrm{~kg}$ cada. Os dados são apresentados por média \pm DP (desvio padrão). As medianas foram comparadas entre si pelo teste de Kruskal-Wallis, adotando-se o nível de significância de $5 \%$. Comparações pareadas foram realizadas por teste U de Mann-Whitney.

Foi utilizado, na análise estatística, o pacote XLStatistics, desenvolvido por Carr (CARR, 2004).

\section{Resultados e discussão}

Em todos os tratamentos, o $\mathrm{pH}$ se manteve próximo a 5,5 e a temperatura dos sistemas, em média, a $22,3^{\circ} \mathrm{C}$, exceto quando se utilizava o ultra-som, cujo sistema aquecia fracamente, fazendo com que chegasse a $24,4{ }^{\circ} \mathrm{C}$.

Os resultados dos tratamentos foram avaliados apenas em relação ao controle.

Não foram encontrados, na literatura, trabalhos utilizando o ozônio ou o ultra-som durante o processamento do café, não sendo possível, portanto, confrontar os dados obtidos com outros autores. Os resultados são mostrados na Tabela 2 e nas Figuras de 1 a 18.

\subsection{Análises microbiológicas}

As contagens totais de microrganismos são utilizadas como parâmetros da carga microbiana presente, não indicando se a população tem efeito prejudicial ou benéfico. Contudo, servem como um alerta das condições de higiene durante a manipulação e armazenamento, como também dos potenciais riscos à saúde do consumidor.

Em adição (dados não analisados estatisticamente), os valores médios encontrados na água utilizada no experimento

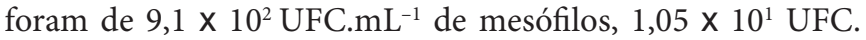
$\mathrm{mL}^{-1}$ de fungos filamentosos e leveduras, acima de $2,4 \times 10^{3}$ NMP. $100 \mathrm{~mL}^{-1}$ de coliformes a $35^{\circ} \mathrm{C}$ e $1,0 \times 10^{0} \mathrm{NMP} .100 \mathrm{~mL}^{-1}$ de coliformes a $45^{\circ} \mathrm{C}$. No café, antes do processamento, foram encontrados em cada grama os valores médios de 3,6 $\times 10^{5} \mathrm{UFC}$ de mesófilos, 8,2 $\times 10^{6}$ UFC de fungos filamentosos e leveduras, acima de $2,4 \times 10^{3} \mathrm{NMP}$ de coliformes a $35^{\circ} \mathrm{C}$ e 6,0 $\times 10^{1} \mathrm{NMP}$ de coliformes a $45^{\circ} \mathrm{C}$.

\section{Contagem padrão de microrganismos mesófilos}

Na contagem padrão em placa de mesófilos, não houve diferença estatística significativa $(\mathrm{p}>0,05)$ entre o controle (café fermentado) e os tratados (Figura 1).

Cardoso et al. (2003) demonstraram a eficácia da água ozonizada no tratamento de galões de água mineral, em rela-
Tabela 2. Valores médios obtidos nas análises de amostras de café fermentado (FER), tratado previamente com ozônio $(\mathrm{OZ}+\mathrm{FER})$ e ultra-som (US + FER).

\begin{tabular}{|c|c|c|c|c|}
\hline \multirow[t]{2}{*}{ Análises } & \multirow[t]{2}{*}{ Unidades } & \multicolumn{3}{|c|}{ Tratamentos } \\
\hline & & FER & $\begin{array}{c}\mathrm{OZ}+ \\
\mathrm{FER} \\
\end{array}$ & $\begin{array}{l}\text { US + } \\
\text { FER }\end{array}$ \\
\hline Mesófilos & $\log \mathrm{UFC}_{\mathrm{g}} \mathrm{g}^{-1}$ & 2,17 & 2,83 & 1,23 \\
\hline Coliformes a $35^{\circ} \mathrm{C}$ & NMP.g ${ }^{-1}$ & 4,38 & 4,38 & 4,38 \\
\hline Coliformes a $45^{\circ} \mathrm{C}$ & NMP.g ${ }^{-1}$ & 0,90 & $0,36^{*}$ & $0,45^{\star}$ \\
\hline $\begin{array}{l}\text { Fungos filam. e } \\
\text { leveduras }\end{array}$ & $\log$ UFC. $g^{-1}$ & 4,54 & $3,56^{*}$ & $3,74^{*}$ \\
\hline Sólidos solúveis & $\%$ & 34,38 & $32,71^{\star}$ & $32,50^{*}$ \\
\hline Acidez titulável & $\begin{array}{c}\mathrm{mL} \mathrm{NaOH} \\
0,1 \mathrm{~N} \text { por } 100 \mathrm{~g}\end{array}$ & 229,17 & 239,58 & 226,56 \\
\hline $\mathrm{pH}$ & & 5,69 & 5,71 & 5,73 \\
\hline Açúcares totais & $\%$ & 12,18 & $10,67^{\star}$ & $9,02^{*}$ \\
\hline $\begin{array}{l}\text { Açúcares } \\
\text { não-redutores }\end{array}$ & $\%$ & 11,34 & $9,94^{*}$ & $8,36^{*}$ \\
\hline Açúcares redutores & $\%$ & 0,25 & $0,21^{*}$ & $0,22^{*}$ \\
\hline Compostos fenólicos & $\%$ & 5,45 & $5,71^{\star}$ & $5,59^{*}$ \\
\hline Lixiviação de potássio & $\mu \mathrm{S} . \mathrm{cm}^{-1} \cdot \mathrm{g}^{-1}$ & 42,99 & $29,21^{*}$ & 29,08 \\
\hline Condutividade elétrica & $\mu \mathrm{S} . \mathrm{cm}^{-1} \cdot \mathrm{g}^{-1}$ & 134,93 & $104,68^{*}$ & $115,29^{*}$ \\
\hline Poligalacturonase & $\mathrm{U} \cdot \mathrm{g}^{-1} / \mathrm{min}$ & 18,65 & 20,60 & 18,15 \\
\hline Pectinametilesterase & $\mathrm{U} \cdot \mathrm{g}^{-1} / \mathrm{min}$ & 8477,78 & $8155,56^{*}$ & $7733,33^{*}$ \\
\hline Polifenoloxidase & $\mathrm{U} \cdot \mathrm{g}^{-1} / \mathrm{min}$ & 63,25 & 63,53 & 63,50 \\
\hline Avaliação Sensorial & nota & 81,83 & 81,86 & 81,50 \\
\hline Abertura dos grãos & $\%$ & 56,0 & $71,7^{\star}$ & 63,0 \\
\hline
\end{tabular}

*Indica que houve diferença estatística em relação ao controle (fermentação), a 5\% de significância.

ção aos mesófilos. Jyoti e Pandit (2004) relatam a eficácia do ozônio e do ultra-som na redução destes microrganismos em água. Veiga (2003) constatou a eficácia do ozônio e ultra-som na redução logarítmica de aeróbios mesófilos em água de chiller de frangos.

Sabe-se da propriedade do ozônio e do ultra-som em degradar a matéria orgânica presente, formando compostos de baixo peso molecular. Assim, substâncias orgânicas próprias do café, como substâncias pécticas, açúcares, celulose, lignina e outras, poderiam estar sendo degradadas a compostos com maior facilidade de assimilação pelos microrganismos, favorecendo seu desenvolvimento durante o processo de fermentação. Este atributo do ozônio é apontado na literatura, mostrando a degradação da lignina em matéria orgânica natural (YAVICH et al., 2004) e seu efeito em talos de milho (QUESADA; RUBIO; GÓMEZ, 1998) e algodão (YOSEF et al., 1994), reduzindo compostos complexos em outros de menor peso molecular.

Além disso, o ozônio tem efeito dispersante em microrganismos agrupados e aderidos a superfícies de alimentos, causando um aumento virtual do número de microrganismos, da mesma forma como sugerido por Velano et al. (2001).

Igualmente, o ultra-som possui propriedades de degradação de matéria orgânica (GONZE et al., 1999) e, ao tratar matéria orgânica de efluente de indústria alimentícia com ultra-som, houve um aumento temporário no crescimento de biomassa, seguido por um decréscimo deste crescimento, acompanhado da degradação dos compostos orgânicos (SCHLÄFER et al., 2002). 

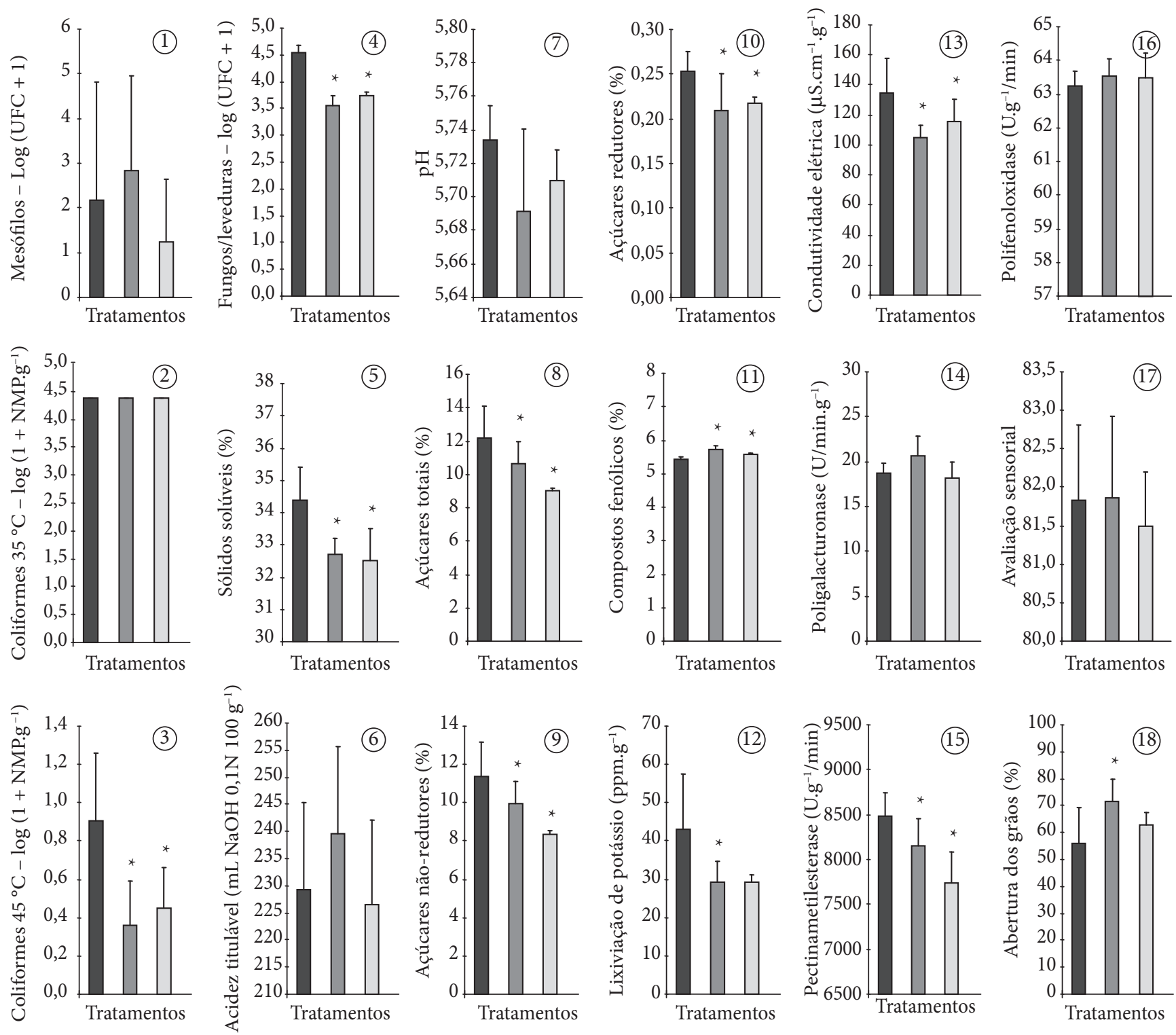

$\square$ FER $\square$ OZ + FER $\square$ US + FER

Figuras 1-18. 1) Valores médios de bactérias aeróbias; 2) coliformes a $35^{\circ} \mathrm{C}$; 3) coliformes a $45^{\circ} \mathrm{C}$; 4) fungos filamentosos e leveduras; 5) sólidos solúveis; 6) acidez titulável; 7) pH; 8) açúcares totais; 9) açúcares não-redutores; 10) açúcares redutores; 11) compostos fenólicos; 12) lixiviação de potássio; 13) condutividade elétrica; 14) poligalacturonase; 15) pectinametilesterase; 16) polifenoloxidase; 17) avaliação sensorial; e 18) abertura dos grãos em amostras de café fermentado, tratado previamente com ozônio e ultra-som. OZ = ozônio, US = ultra-som, FER = fermentação; e ${ }^{\star}$ Indica que houve diferença estatística em relação ao controle (fermentação), a 5\% de significância.

Jyoti e Pandit (2004) e Seymour et al. (2002) citam também esta propriedade de desagregação dos microrganismos com o emprego de ultra-som. Isso justificaria os valores oscilantes na contagem de microrganismos encontrada neste trabalho, pois provavelmente o ultra-som, assim como o ozônio, estaria degradando os compostos orgânicos do café (devendo a mucilagem que envolve os grãos de café a primeira a sofrer sua ação), aumentando a taxa de açúcares e outros compostos assimiláveis pelos microrganismos e dispersando os mesmos, porém com tempo e/ou freqüência insuficiente para degradá-los.

Portanto, é previsto aumento inicial e, como se verifica na revisão feita por Nascimento et al. (2005), também é previsto decréscimo da contagem de microrganismos com o decorrer do tratamento com ultra-som.

A tendência a menores valores de mesófilos nos tratamentos prévios com ozônio e ultra-som, seguidos de fermentação, 
pode ser devido ao $\mathrm{pH}$ reduzido na fermentação (AVALLONE et al., 2001).

Pelo exposto, e sabendo-se que o ozônio e o ultra-som são capazes de reduzir e eliminar microrganismos (CARDOSO et al., 2003; VEIGA, 2003), sugere-se que o tempo dos tratamentos propostos foi insuficiente para tal, haja vista a grande quantidade de matéria orgânica resultante do tratamento e também a quantidade de grãos que certamente diminuiram a ação destes tratamentos.

Observando-se a Figura 1, podem ser notados ainda desvios padrão menores nos tratamentos, principalmente com ultra-som, sugerindo uma melhor padronização no processo de retirada de mucilagem do café, se comparado com a fermentação.

\section{Contagem de leveduras e fungos filamentosos}

$\mathrm{Na}$ contagem de fungos filamentosos e leveduras, observase que houve redução significativa $(p<0,05)$ nas amostras tratadas em relação ao café controle (fermentado) (Figura 4).

Vários autores demonstraram a eficiência do ozônio e do ultra-som na redução de fungos filamentosos e leveduras em água, frutas e outros vegetais (IDRISSI et al., 1996; NASCIMENTO et al. 2005; PALOU et al., 2002; RADEL, 2000; SARIG et al.,1996).

No presente trabalho, comprova-se a eficiência dos tratamentos por ozônio e/ou ultra-som no café, pela diminuição na contagem de células fúngicas que podem causar danos à saúde do consumidor.

Como já discutido anteriormente, o ozônio e o ultra-som possuem propriedades microbicidas e também dispersantes de microrganismos. Assim, provavelmente houve nos tratamentos ação dispersante de ambos em relação aos fungos filamentosos e leveduras, mas não houve tempo ou poder de ação suficiente do ozônio e do ultra-som para uma inativação mais pronunciada dos microrganismos em questão. Mesmo assim, são evidentes suas ações e conseqüente acréscimo à segurança alimentar em produtos por eles tratados.

\section{Determinação do NMP de coliformes e E. coli}

$\mathrm{Na}$ determinação de contagem daqueles atualmente denominados coliformes a $35^{\circ} \mathrm{C}$, observa-se que não houve redução significativa $(\mathrm{p}<0,05)$ nas amostras tratadas (Figura 2$)$.

Como se verifica na Figura 3, na determinação do NMP de E. coli, observa-se que houve redução estatisticamente significativa $(\mathrm{p}<0,05)$ nos tratamentos.

Bactérias gram-negativas, como Escherichia, Enterobacter, Erwinia e Klebsiella, são comumente distribuídas no ambiente e são encontradas no café. Assim, durante a fermentação do café, há o desenvolvimento destes coliformes (AVALLONE et al., 2001; 2002; SILVA et al., 2000). Admite-se que o ozônio dissolvido em água seja muito eficiente para reduzir ou eliminar coliformes (JYOTI; PANDIT, 2003; NASCIMENTO et al., 2005; VEIGA, 2003; VELANO et al., 2001), bem como o emprego do ultra-som (JYOTI; PANDIT, 2003; VEIGA, 2003). Nas amostras que, após tratadas pelo ozônio ou ultra-som, seguiu-se um período de fermentação (OZ + FER e US + FER), aliado aos fatos da utilização de água não tratada neste período e também na lavagem final das amostras, além da exposição das amostras ao ambiente, supõe-se que houve o crescimento destes microrganismos (remanescentes ou não dos tratamentos iniciais) que se desenvolveram rapidamente, durante o período de fermentação, com o auxílio de produtos assimiláveis gerados pela degradação de matéria orgânica. Assim, nestes tratamentos, não houve redução da contagem de coliformes a $35^{\circ} \mathrm{C}$ (Figura 2), mas ocorreu redução na detecção de E. coli (Figura 3).

Deve ser considerado também, que durante os tratamentos com ozônio e ultra-som, pela alta reatividade da hidroxila formada, possivelmente pode ocorrer a produção de diversas substâncias, dentre as quais alguma com atividade antimicrobiana e com probabilidade de ser mais específica para determinados microrganismos.

Mesmo sem tratamento, as amostras estavam aquém do aceitável, de acordo com as normas vigentes (BRASIL, 2001), em termos de coliformes a $45^{\circ} \mathrm{C}$ ou preferencialmente E. coli. Mas, considerando a redução obtida para coliformes, fungos filamentosos e leveduras, principalmente nos tratamentos sem fermentação, pode ser sugerido que os tratamentos propostos melhoram a qualidade microbiológica do café. Assim, extrapolando-se os resultados obtidos e considerando que as bactérias patogênicas são mais sensíveis que as bactérias indicadoras (HACH, 1998), os tratamentos com ozônio e/ou com ultra-som poderão ser grandes aliados no combate aos microrganismos que levam a uma deterioração da qualidade e da segurança alimentar do café.

\subsection{Análises de qualidade do café}

\section{Sólidos solúveis totais}

$\mathrm{Na}$ análise de sólidos solúveis, oberva-se que houve redução significativa $(\mathrm{p}<0,05)$ nos tratamentos prévios com ozônio e ultra-som (Figura 5).

Os sólidos solúveis são desejáveis em altas quantidades no café devido à sua relação direta com o corpo da bebida (VILLELA, 2002), e nos resultados deste estudo houve diminuição nos tratamentos (OZ + FER e US + FER), mas com valores dentro ou acima da faixa encontrada por diversos autores (MENDONÇA; PEREIRA; MENDES, 2005; PÁDUA, 2002; VILLELA, 2002). Sugere-se assim, que os tratamentos propostos alteraram estes valores no café, porém não de forma acentuada que pudesse influenciar a bebida.

\section{Acidez titulável (AT)}

$\mathrm{Na}$ análise de acidez titulável, não houve diferença significativa $(p>0,05)$ entre os tratamentos (Figura 6).

Carvalho et al. (1994) e Pereira (1997) notaram haver uma relação inversa entre qualidade dos grãos de café e valores de acidez, sendo maior a acidez encontrada em cafés de pior qualidade. 
Neste trabalho, foram utilizadas amostras de café da região Sul de Minas, que é uma região de cafés com menores teores de acidez (SOUZA, 1996).

O valor da acidez titulável está relacionado com a concentração total de ácidos na amostra (FRANCIS, 2000). Considerando que o ozônio e o ultra-som degradam a matéria orgânica, levando à produção de ácidos, como fórmico e acético (GONZE et al., 1999; YOSEF et al., 1994), supunha-se que haveria aumento significativo de acidez titulável. Entretanto, o tempo de aplicação do ozônio e do ultra-som não foi suficiente para que houvesse intensa degradação, com formação de ácidos capazes de alterar a acidez titulável de modo apreciável.

$p H$

$\mathrm{Na}$ análise de $\mathrm{pH}$, os resultados mostraram não haver diferença significativa $(\mathrm{p}>0,05)$ entre os tratamentos (Figura 7).

A acidez aparente ou livre acidez $(\mathrm{pH})$ é importante na qualidade da bebida por ser perceptível ao sabor (SIVETZ, 1963).

A tendência a valores menores de $\mathrm{pH}$ nas amostras que passaram pelo processo de fermentação talvez possa ser explicada pelo próprio processo, cuja característica é o abaixamento de $\mathrm{pH}$. Mas, as diferenças entre os diversos tratamentos foram irrelevantes, levando a inferir que os tratamentos propostos não alteraram os valores de $\mathrm{pH}$ das amostras.

\section{Açúcares totais, redutores e não redutores}

$\mathrm{Na}$ análise de açúcares totais, houve redução significativa $(\mathrm{p}<0,05)$ ou mesmo tendência à diminuição nos tratamentos, quando comparados ao controle (café fermentado) (Figura 8).

$\mathrm{Na}$ análise de açúcares não redutores houve diferença significativa $(\mathrm{p}<0,05)$ em todos os tratamentos (Figura 9).

$\mathrm{Na}$ análise de açúcares redutores foi verificada diferença estatística significativa $(\mathrm{p}<0,05)$ em todos os tratamentos (Figura 10).

Entre outros autores, Illy e Viani (1995) concordam em afirmar que maiores teores de açúcares propiciam melhor qualidade na bebida.

O ozônio tem a capacidade de hidrolisar parte da celulose da parede celular a açúcares (TOCK et al., 1982), bem como de outros polissacarídeos (QUESADA; RUBIO; GÓMEZ, 1998). Portanto, esta propriedade poderia estar causando uma liberação mais facilitada da mucilagem e de seus constituintes, que provavelmente foram carreados com a água desprezada após o tratamento com o ozônio, justificando a diminuição dos teores de açúcares com este tratamento. Além disso, a redução no teor de carboidratos na mucilagem diminui a transferência destes para o interior dos grãos durante o processo de fermentação (CARVALHO, 1997).

Alguns artigos mostram a eficácia do ultra-som para a extração de polissacarídeos (EBRINGEROVÁ; HROMÁDKOVÁ, 2002; MECOZZI et al., 1999). Além disso, o ultra-som tem o poder também de extrair açúcar pela combinação dos efeitos de ruptura de parede celular e aumento da transferência de massa, devido ao aumento de penetração do solvente (MASON; PANIWNYK; LORIMER, 1996). A diminuição no teor de açúcares das amostras tratadas com ultra-som pode ser explicada também pelo efeito carreador da água utilizada durante este tratamento.

\section{Compostos fenólicos}

A análise de compostos fenólicos apresentou elevação estatisticamente significativa $(\mathrm{p}<0,05)$ em todos os tratamentos propostos (Figura 11), sendo maior com o emprego do ozônio, seguido do ultra-som e apenas fermentado.

Os compostos fenólicos são responsáveis pela adstringência dos frutos, e sua concentração é inversamente proporcional à qualidade da bebida (COSTA; CHAGAS, 1997).

$\mathrm{O}$ que poderia ter contribuído para o aumento do teor destes compostos nas amostras tratadas com ozônio seria a degradação de polímeros fenólicos, como a lignina. De fato, Quesada et al. (1998) e Wiese e Pell (2003) apresentaram resultados de degradação de lignina por ozônio, formando vários compostos, entre eles, fenólicos mais simples, como derivados de ácidos benzóico e cinâmico.

O ozônio é altamente reativo com compostos fenólicos, como observado por vários autores (BENITEZ et al., 2003; NAFFRECHOUX et al., 2000). Assim, pode-se aventar a hipótese de que o tempo foi insuficiente para degradar os compostos liberados dos polímeros durante o tratamento das amostras de café.

A degradação de compostos fenólicos também foi obtida pelo uso do ultra-som na decomposição de matéria orgânica de efluentes (BENITEZ et al., 2003; NAFFRECHOUX et al., 2000), lignina em milho (EBRINGEROVÁ; HROMÁDKOVÁ, 2002) e fenol (GOGATE; PANDIT, 2004). Como sugerido para o tratamento com ozônio, acredita-se que o tempo também foi insuficiente para degradar os compostos fenólicos, devido à alta concentração de matéria orgânica.

Assim, possivelmente nos tratamentos propostos, o ozônio e o ultra-som degradaram parcialmente os polímeros dos grãos, deixando mais livres vários compostos, inclusive os fenólicos, o que explicaria seu aumento significativo nos mesmos, principalmente na combinação de ambos os tratamentos, mas não havendo tempo de ação suficiente para degradá-los.

\section{Lixiviação de potássio}

A análise de lixiviação de potássio apresentou diferença estatisticamente significativa $(\mathrm{p}<0,05)$ apenas para o grupo $\mathrm{OZ}+$ FER (redução) em relação ao grupo apenas fermentado (Figura 12).

O ozônio é um gás altamente reativo que pode levar à formação de radicais livres e a um aumento no potencial oxidativo das células (PELL; ECKARDT; GLICK, 1994). A toxicidade do ozônio tem sido atribuída aos efeitos danosos nos componentes de membrana, resultando no aumento da sua permeabilidade (RUNECKLES; CHEVONE, 1992). 
O ultra-som também provoca efeitos danosos nas membranas, além de possuir um mecanismo químico, pela formação de radicais livres e peróxido de hidrogênio (ENTEZARI; NAZARY; KHODAPARAST, 2004).

Nos tratamentos prévios com ozônio e ultra-som (OZ + FER e US + FER), houve redução nos valores de lixiviação de potássio, podendo ser proposto que nos grãos de café a degradação pelo ozônio ocorra primeiramente na mucilagem e, posteriormente, durante a sua penetração através da membrana. A presença de antioxidantes, como polifenóis (principalmente ácido clorogênico), no café (DUARTE, 2004), provavelmente contribui para a defesa do mesmo da ação lesiva de substâncias oxidantes, como o ozônio. Os polifenóis agem como efetivos seqüestrantes de radicais livres e protegem o grão de seus efeitos danosos, sendo, portanto, eficientes na defesa contra o ozônio e seus produtos de reação.

Por outro lado, a ação quelante de metais pelos polifenóis (DUARTE, 2004) poderia contribuir também para uma menor lixiviação de íons. Os dados do presente trabalho induzem a concluir que os tratamentos prévios com ozônio e ultra-som (OZ + FER e US + FER) não alteraram, em vez de aumentarem, a permeabilidade da membrana do café, o que foi demonstrado pela menor lixiviação de potássio. Sugere-se, portanto, que o potencial danoso do ozônio sobre a membrana pode ter sido mascarado por ter sido retida certa quantidade de potássio no grão, devido à ação quelante de polifenóis. Embora o valor relativo de cátions dissolvidos em água não tenha sido alterado significativamente com o tratamento pelo ozônio, não pode ser afirmado que a concentração total de potássio no grão não tenha sido aumentada. O potássio está primeiramente presente no citoplasma, e somente pequenas concentrações de potássio estão ligadas a grupos funcionais na parede celular. Por fim, pode ser sugerido ainda que o tempo de exposição ao ozônio e ao ultra-som nestes tratamentos (OZ + FER e US + FER) não tenha sido suficiente para causar injúria severa, uma vez que a quantidade de matéria orgânica liberada pode ter reduzido a ação dos mesmos.

Beckerson e Hofstra (1980) encontraram que a exposição a 150 ppb de ozônio causou significativo aumento na liberação de solutos da soja e do feijão branco, medida por condutividade elétrica. Ao ser comparado a estes grãos, o café parece ser menos sensível ao ozônio. Embora o nível de ozônio capaz de penetrar no interior de tecidos seja desconhecido, a ocorrência dessa menor sensibilidade ao ozônio poderia ser relacionada ao maior teor de polifenóis encontrado no café (DUARTE, 2004).

\section{Condutividade elétrica}

$\mathrm{Na}$ análise de condutividade elétrica, observa-se redução estatisticamente significativa $(\mathrm{p}<0,05)$ nos tratamentos prévios seguidos de fermentação (OZ + FER e US + FER) (Figura 13).

Sabe-se que a condutividade elétrica aumenta com danos causados à integridade das membranas celulares, sendo considerada um indicador consistente desta integridade (RIBEIRO, 2003). Acreditava-se, portanto, que o valor da condutividade elétrica aumentaria com o uso de ozônio ou do ultra-som, mas curiosamente isso não ocorreu nos tratamentos prévios com ozônio e ultra-som (OZ + FER e US + FER), apesar do alto poder de degradação de membranas de ambos (JYOTI; PANDIT, 2003; 2004; MASON et al., 2003).

A condutividade elétrica está diretamente relacionada com a lixiviação de potássio, pois com as injúrias sofridas pelos grãos de café, o íon mais lixiviado para o exterior das células é o potássio. Isso justifica o comportamento idêntico de ambos em relação aos tratamentos propostos. E da mesma forma que a condutividade elétrica, surpreendentemente houve diminuição da lixiviação de potássio nos tratamentos $\mathrm{OZ}+$ FER e US + FER.

Vários íons estão presentes no café, principalmente o potássio, sendo responsável por $40 \%$ do total de íons. Estão presentes também: o magnésio, o rubídio, o cobre, o manganês, o cálcio e o ferro, entre outros (ILLY; VIANI, 1995).

Está bem documentada a propriedade da molécula de polifenol formar fortes complexos com íons metálicos, como ferro, manganês, alumínio, cálcio, sódio, potássio e magnésio (DUARTE, 2004; HASLAN, 1996).

A ação do ozônio e do ultra-som, como já sugerido, pode ter aumentado a concentração de fenóis, que apresentam uma grande capacidade de complexação com íons metálicos. Portanto, embora tenha havido ação destrutiva dos tratamentos prévios com ozônio e ultra-som sobre a membrana celular, o poder quelante exercido pela maior concentração de fenóis impediria o aumento da condutividade elétrica, o que não ocorreu com o café apenas fermentado (FER). Desse modo, a redução da condutividade elétrica se deveria mais ao poder quelante de metais dos ácidos clorogênicos que a um verdadeiro efeito protetor do ozônio e do ultra-som na membrana celular.

A grandeza condutividade elétrica, provavelmente, é mesmo influenciada por muitos fatores (FAVARIN et al., 2004) e não deve ser correlacionada com a bebida de café ou a integridade de membranas, pura e simplesmente. Mas, deve ser levado em consideração o teor de polifenóis existente no grão do café.

\section{Enzima poligalacturonase ( $P G)$}

$\mathrm{Na}$ análise de poligalacturonase (EC 3.2.1.15), observa-se que não houve diferença estatisticamente significativa $(\mathrm{p}<0,05)$ nos tratamentos prévios seguidos de fermentação $(\mathrm{OZ}+\mathrm{FER}$ e US + FER) (Figura 14).

Sabe-se que o ozônio produz radicais hidroxila e peróxido, que provocam a cisão de polissacarídeos (QUESADA; RUBIO; GÓMEZ, 1998; TOCK et al., 1982), podendo ser considerado um mecanismo alternativo não enzimático para a despolimerização ou solubilização dos mesmos (DUMVILLE; FRY, 2003; ENTEZARI; NAZARY; KHODAPARAST, 2004). A produção de radicais hidroxila e peróxido também é obtida com o emprego do ultra-som (MECOZZI et al., 1999). Assim, sugere-se que o ozônio e o ultra-som, agindo nas amostras de café, poderiam ter degradado parte da pectina, formando polissacarídeos menores e mais acessíveis à poligalacturonase, possivelmente aumentando sua ação. 
No entanto, nos tratamentos prévios com ozônio e ultrasom, seguidos de fermentação (OZ + FER e US + FER), foram obtidos resultados semelhantes aos da fermentação, justamente por terem sido tratamentos menos drásticos, devido à presença de grande quantidade de matéria orgânica no sistema.

\section{Enzima pectinametilesterase (PME)}

$\mathrm{Na}$ análise de pectinametilesterase (EC 3.1.1.11), observase, na Figura 15, redução estatisticamente significativa $(\mathrm{p}<0,05)$ nos tratamentos prévios seguidos de fermentação $(\mathrm{OZ}+\mathrm{FER}$ e US + FER).

São sugestivas as ações do ozônio e do ultra-som como tratamento de amostras de café antes da fermentação $(\mathrm{OZ}+\mathrm{FER}$ e US + FER), diminuindo significativamente a atividade de pectinametilesterase. Como já sugerido no tópico anterior, a produção de radicais hidroxila e peróxidos, pelo ozônio e ultra-som, pode ter solubilizado e degradado parte da pectina, diminuindo a quantidade de grupos metílicos e, portanto, diminuindo a atividade da pectinametilesterase. Não foram encontrados dados de pesquisa semelhantes para confrontar com os encontrados no presente trabalho. As oscilações encontradas nos diversos tratamentos podem ser devido à produção de grande quantidade de matéria orgânica.

Nos resultados obtidos, foi observada redução na atividade desta enzima, possivelmente pela geração de radicais livres que podem ter causado desmetilação do $\mathrm{C}_{6}$ da pectina, onde a PME atua.

\section{Enzima polifenoloxidase (PFO)}

$\mathrm{Na}$ análise de polifenoloxidase (EC 1.14.18.1), observa-se, na Figura 16, que não há redução estatisticamente significativa $(\mathrm{p}<0,05)$ nos tratamentos.

A injúria sobre a membrana celular, provocada por microrganismos durante a fermentação, libera e, portanto, ativa a enzima polifenoloxidase, que por sua vez oxida compostos fenólicos a quinonas, as quais, quando em teor representativo, atuam inibindo a polifenoloxidase, diminuindo sua atividade (ILLY; VIANI, 1995; PIMENTA, 2001). Com a ação da polifenoloxidase sobre os polifenóis, diminui a ação destes na proteção contra a oxidação dos aldeídos, podendo afetar, de forma negativa, a qualidade da bebida (PIMENTA, 1995). Portanto, aumentando a atividade desta enzima, houve maior injúria do café e conseqüente perda na qualidade da bebida.

Com a utilização antecipada do ozônio e também do ultra-som (OZ + FER e US + FER), houve uma redução de microrganismos e, conseqüentemente, uma redução da injúria. Por outro lado, a ação lesiva do ozônio e do ultra-som sobre a membrana celular, embora presente, é reduzida pelo efeito dos mesmos na mucilagem, promovendo quebra na estrutura, funcionando como uma primeira barreira e protegendo a membrana celular.

Portanto, a atividade da enzima permaneceu com valores semelhantes, embora por mecanismos diferentes. Houve um equilíbrio: por um lado, a ação de grande quantidade de microrganismos na membrana celular do café apenas fermentado e, por outro, o efeito aditivo provocado pela menor concentração de microrganismos mais o efeito direto dos tratamentos sobre a membrana celular, mas amenizado pela presença de mucilagem.

\subsection{Análises sensoriais}

$\mathrm{Na}$ análise sensorial da bebida, os valores médios obtidos nas avaliações feitas pela prova de xícara das amostras de café fermentado (FER), tratado previamente com ozônio, seguido de fermentação (OZ + FER) e previamente com ultra-som, seguido de fermentação (US + FER) não apresentaram diferenças estatísticas significativas $(p>0,05)$ entre os tratamentos propostos, como pode ser observado na Figura 17.

O tratamento de alimentos com ozônio e ultra-som é citado por vários autores como não interferindo na avaliação sensorial, como Oliveira (2005), tratando tilápias com ozônio e ultra-som; Veiga (2003), tratando carcaças de frango também com ozônio e ultra-som; Manousaridis et al. (2005), tratando moluscos com ozônio; Wang et al. (2004), tratando coentro com ozônio; entre outros.

Os atributos avaliados isoladamente (bebida limpa, sabor, aftertaste, doçura, corpo, acidez, balanço e geral) e que deram origem às notas finais das amostras de café plotadas na Figura 17, obtiveram notas entre aproximadamente 5 e 6 (dados não mostrados), ou seja, boas e finas, respectivamente. Na somatória, todas as amostras obtiveram valores próximos de 81 , ou seja, todas foram julgadas como amostras de café especial, cuja nota deve ser superior a 80, como aceito no comércio deste tipo de café. Os resultados sugerem, portanto, que as amostras em que foram aplicados os tratamentos propostos não mostraram alterações perceptíveis na avaliação sensorial, podendo ser consideradas, dentro da classificação de cafés especiais, como de padrão médio.

Apesar de alguns parâmetros de qualidade analisados neste trabalho sugerirem um decréscimo na qualidade da bebida, não houve diferenças drásticas que pudessem causar uma depreciação excessiva na avaliação sensorial. Deve ser considerado também que, além de subjetiva, esta avaliação é feita após a torração que mascara defeitos em amostras de café.

\subsection{Abertura dos grãos}

$\mathrm{Na}$ análise de abertura de grãos de café após a torra, típica de cafés despolpados, os resultados mostraram diferenças estatísticas significativas $(\mathrm{p}<0,05)$ somente nos tratamentos das amostras de café com ozônio, seguidos de fermentação (Figura 18).

A torração do café é considerada como característica de café despolpado quando a maioria dos grãos apresenta a "membrana prateada" ou a "película branca", clara e bem nítida no sulco ventral dos grãos (ZANOTTI; SOUSA NETO, 2005). No comércio do café despolpado, esta é a única forma de classificadores de cafés conseguirem distinguir entre cafés despolpados e os obtidos por outros processos após a torra (informação pessoal).

Com os tratamentos utilizados, a quantidade de grãos com a mesma característica de cafés despolpados foi maior com o 
ozônio e semelhante quando utilizado o ultra-som (mas com tendência a aumentar). Provavelmente, a atuação destes dois tratamentos alterou a textura dos grãos, facilitando a abertura dos mesmos e expondo a camada germinativa do embrião. Sugere-se então, que o tratamento prévio com ozônio e ultrasom reproduz esta característica de café despolpado, sendo útil na comercialização, pois o mercado valoriza mais o café fermentado.

\section{Conclusões}

Em função dos resultados obtidos, conclui-se que o emprego do ozônio ou do ultra-som como tratamento prévio ao processo de obtenção de café despolpado (fermentação) poderá ser um possível aliado à segurança alimentar. Além disso, os tratamentos propostos não alteraram, de modo depreciável, a qualidade do café.

\section{Agradecimentos}

Os autores agradecem às empresas: Fapemig, Unifenas, Unifal-MG, UFLA, White White Martins Gases Industriais S/A e Ipanema Agrícola S/A.

\section{Referências bibliográficas}

ABCE. Associação Brasileira de Cafés Especiais. Cup of excellence 2003. Alfenas: BSCA, 2003.

AHMAD, R.; THARAPPAN, B.; BONGIRWAR, D. R. Impact of gamma irradiation on the monsooning of coffee beans. Journal of Stored Products Research, Oxford, v. 39, n. 2, p. 149-157, 2002.

AOAC. Association of Official Analytical Chemists. Official methods of analysis. 15. ed. Washington: AOAC, 1990. 1115 p.

APHA. American Public Health Association. Standard Methods for Examination of Water and Wastewater. 18 ed. Washington: APHA, 1992. 1268p.

AVALLONE, S. et al. Involvement of pectolytic micro-organisms in coffee fermentation. International Journal of Food Science and Technology, Oxford, v. 37, n. 2, p. 191-198, Feb. 2002.

. Microbiological and biochemical study of coffee fermentation. Current Microbiology, New York, v. 42, n. 4, p. 252-256, Apr. 2001.

BATISTA, L. R. et al. Toxigenic fungi associated with processed (green) coffee beans (Coffea arabica L.). International Journal of Food Microbiology, Amsterdam, v. 85, n. 3, p. 293- 300, Aug. 2003.

BECKERSON, D. W.; HOFSTRA, G. Effects of sulphur dioxide and ozone, singly or in combination, on membrane permeability. Canadian Journal of Botany, Ottawa, v. 58, n. 4, p. 451-457, 1980.

BENITEZ, F. J. et al. Purification of cork processing wastewaters by ozone, by activated sludge, and by their two sequential applications. Water Research, Oxford, v. 37, n. 17, p. 4081-4090, Oct. 2003.

BEUCHAT, L. R. et al. Inactivation of aflatoxigenic Aspergilli by treatment with ozone. Letters in Applied Microbiology, Oxford, v. 29, n. 4, p. 202-205, 1999.

BRASIL. Agência Nacional de Vigilância Sanitária. RDC n. 12: Regulamento técnico sobre padrões microbiológicos para alimentos. Brasília: ANVISA, 2001. Disponível em: <http://www.anvisa.gov.br/ legis/resol/12_01rdc.htm >. Acesso em: 15 abr. 2008.
CARDOSO, C. C. et al. Avaliação microbiológica de um processo de sanificação de galões de água com a utilização do ozônio. Ciência e Tecnologia de Alimentos, Campinas, v. 23, n. 1, p. 59-61, jan./ abr. 2003.

CARR, R. XLStatistics: statistics analysis workbooks for Microsoft Excel. Versão 5. 73 (2004), XLent Works, 2004. Disponível em: $<$ http://www.deakin.edu.au/ rodneyc/XLStats.htm>. Acesso em: 25 jul. 2004.

CARVALHO, V. D. Qualidade do café. Lavras: Faepe-UFLA, 1997. $37 \mathrm{p}$.

CARVALHO, V. D. de et al. Relação entre a composição físico-química e química do grão beneficiado e a qualidade da bebida do café. Pesquisa Agropecuária Brasileira, Brasília, v. 29, n. 3, p. 449-454, mar. 1994

COFFEE TALK. The world of coffee. The New Java U. Vashon, WA, USA: Coffee Talk, 2002. p. 23-49. Disponível em: <http://www. coffeetalk.com//images/2_The_World_of_Coffee.pdf >. Acesso em: 10 fev. 2008.

COSTA, L.; CHAGAS, S. J. R. Gourmets - uma alternativa para o mercado de café. Informe Agropecuário, Belo Horizonte, v. 18, n. 187, p. 63-67, 1997.

DRAETTA, I. S.; LIMA, D. C. Isolamento e caracterização das polifenoloxidases do café. Coletânea do Instituto de Tecnologia de Alimentos, Campinas, v. 7, p. 13-28, 1976.

DUARTE, S. M. S. Atividade antioxidante e antimutagênica in vitro e in vivo da bebida do café. Lavras, 2004. 118 p. Tese (Doutorado em Ciência dos Alimentos) - Universidade Federal de Lavras.

DUMVILLE, J. C.; FRY, S. C. Solubilisation of tomato fruit pectins by ascorbate: a possible non-enzymic mechanism of fruit softening. Planta, Berlin, v. 217, n. 6, p. 951-961, Oct. 2003.

EBRINGEROVÁ, A.; HROMÁDKOVÁ, Z. Effect of ultrasound on the extractibility of corn bran hemicelluloses. Ultrasonics Sonochemistry, Amsterdam, v. 9, n. 4, p. 225-229, Sept. 2002.

EMBRAPA - Empresa Brasileira de Pesquisa Agropecuária. Consórcio Brasileiro de Pesquisa e Desenvolvimento do café: relatório de gestão. Brasília: Ministério da Agricultura, Pecuária e Desenvolvimento, [2004?]. 142 p. Disponível em: <http://www22. sede.embrapa.br/cafe/outros/arq_Relat_Gestao/ Tecnologias_ PARTE1.pdf > . Acesso em: 10 fev. 2008.

ENTEZARI, M. H.; NAZARY, S. H.; KHODAPARAST, M. H. H. The direct effect of ultrasound on the extraction of date syrup and its micro-organisms. Ultrasonics Sonochemistry, Amsterdam, v. 11, n. 6, p. 379-384, Sept. 2004.

FAVARIN, J. L. et al. Qualidade da bebida de café de frutos cereja submetidos a diferentes manejos pós-colheita. Pesquisa Agropecuária Brasileira, Brasília, v. 39, n. 2, p. 187-192, fev. 2004.

FRANCIS, F. J. (Ed.). Encyclopedia of food science and technology. 2. ed. New York: Wiley, 2000. 2907 p.

GOGATE, P. R. ; PANDIT, A. B. A review of imperative technologies for wastewater treatment II: hybrid methods. Advances in Environmental Research, Oxford, v. 8, n. 3-4, p. 553-597, Mar. 2004.

GOLDSTEIN, J. L.; SWAIN, T. Changes in tannins in ripening fruits. Phytochemistry, Oxford, v. 2, n. 4, p. 371-382, 1963.

Gonze, E. et al. Wastewater pretreatment with ultrasonic irradiation to reduce toxicity. Chemical Engineering Journal, Lausanne, v. 73, n. 2, p. 93-100, May 1999. 
HAAHR, M. Randon. org: true random number service. 1999. Disponível em: <http://www.random.org/integers/>. Acesso em: 10 fev. 2008

HACH. Hach: bottled water analysis handbook. Loveland, Colorado (EUA): Hach Company, 1998. 260 p.

Haslan, E. Natural polyphenols (vegetable tannins) as drugs: possible modes of action. Journal of Natural Products, Chicago, v. 59, n. 2, p. 205-215, 1996.

Hicks, P. A. Postharvest processing and quality assurance for speciality / organic coffee products. In: Asian regional round-table on sustainable, organic and speciality coffee production, processing and marketing, 1., 2001, Chiang Mai, Thailand. Papers and Abstracts... Chiang Mai, Thailand: FAO, 2001.

IDRISSI, F. Z. et al. Effect of ultrasound on fungal cells. Cytobios, Cambs, v. 88, n. 353, p. 119-122, 1996.

ILLY, A.; VIANI, R. Expresso coffee: the chemistry of quality. London: Academic Press, 1995. 253 p.

Jyoti, K. K.; Pandit, A. B. Effect of cavitation on chemical disinfection efficiency. Water Research, Oxford, v. 38, n. 9, p. 2249-2258, May 2004.

.Hybrid cavitation methods for water disinfection: simultaneous use of chemicals with cavitation. Ultrasonics Sonochemistry, Amsterdam, v. 10, n. 4-5, p. 255-264, July 2003.

KIM, J. G.; YOUSEF, A. E.; DAVE, S. Application of ozone for enhancing the microbiological safety and quality of foods: a review. Journal of Food Protection, Ames, v. 62, n. 9, p. 1071-1087, Sept. 1999.

LOEFFLER, T. M.; TEKRONY, D. M.; EGLI, D. B. The bulk conductivity test as an indicator of soybean quality. Journal of Seed Technology, Sangamon, v. 12, n. 1, p. 3-6, 1988.

MAEZTU, L. et al. Multivariate methods for characterization and classification of espresso coffees from different botanical varieties and types of roast by foam, taste, and mouthfeel. Journal of Agricultural and Food Chemistry, Washington, v. 49, n. 10-11, p. 4743-4747, Nov. 2001.

Manousaridis, G. et al. Effect of ozone on microbial, chemical and sensory attributes of shucked mussels. Food Microbiology, London, v. 22, n. 1, p. 1-9, 2005.

MASON, T. J. et al. Potential uses of ultrasound in the biological decontamination of water. Ultrasonics Sonochemistry, Amsterdam, v. 10, n. 6, p. 319-323, Oct. 2003.

MASON, T. J.; PANIWNYK, L.; LORIMER, J. P. The uses of ultrasound in food technology. Ultrasonics Sonochemistry, Amsterdam, v. 3, n. 3, p. S253-S260, Nov. 1996.

MECOZZI, M. et al. Ultrasound-assisted analysis of total carbohydrates in environmental and food samples. Ultrasonics Sonochemistry, Amsterdam, v. 6, n. 3, p. 133-139, June 1999.

MENDONÇA, L. M. V. L.; PEREIRA, R. G. F. A.; MENDES, A. N. G. Parâmetros bromatológicos de grãos crus e torrados de cultivares de café (Coffea arabica L.). Ciência e Tecnoloagia de Alimentos, Campinas, v. 25, n. 2, p. 239-243, abr./jun. 2005.

NAFFRECHOUX, E. et al. Sonochemical and photochemical oxidation of organic matter. Ultrasonics Sonochemistry, Amsterdam, v. 7, n. 4, p. 255-259, Oct. 2000.

NASCIMENTO, L. C. et al. Uso de derivados clorados, ozônio e ultra-som na sanificação de água e alimentos - revisão. Higiene Alimentar, São Paulo, v. 19, n. 136, p. 48-57, out. 2005.

NELSON, N. A photometric adaptation of the Somogyi method for the determination of glucose. Journal of Biological Chemistry, Baltimore, v. 153, p. 375-380, 1944.
OLIVEIRA, N. M. S. Ação sanificante do dicloroisocianurato de sódio, ozônio e ultra-ozônio em filés de tilápia (Orechromis niloticus). Lavras, 2005. 156 p. Tese (Doutorado em Ciência dos Alimentos) - Universidade Federal de Lavras.

PÁDUA, F. R. M. Composição química e qualidade de diferentes tipos de café torrado e moído durante o armazenamento. Lavras, 2002. 76 p. Dissertação (Mestrado em Ciência dos Alimentos) Universidade Federal de Lavras.

PALOU, L. et al. Effects of continuous $0.3 \mathrm{ppm}$ ozone exposure on decay development and physiological responses of peaches and table grapes in cold storage. Postharvest Biology and Technology, Amsterdam, v. 24, n. 1, p. 39-48, Jan. 2002.

PELL, E. J.; ECKARDT, N. A.; GLICK, R. E. Biochemical and molecular basis for impairment of photosynthetic potential. Photosynthesis Research, Dordrecht, v. 39, n. 3, p. 453-462, Mar. 1994.

PEREIRA, R. G. F. A. Efeito da inclusão de grãos defeituosos na composição química e qualidade do café (Coffea arabica L.) “estritamente mole". Lavras, 1997. 96 p. Tese (Doutorado em Ciência dos Alimentos) - Universidade Federal de Lavras.

PIMENTA, C. J. Época de colheita e tempo de permanência dos frutos à espera da secagem, na qualidade do café. Lavras, 2001. 145p. Tese (Doutorado em Ciência dos Alimentos) - Universidade Federal de Lavras.

Qualidade do café (Coffea arabica L.) originado de diferentes frutos colhidos em quatro estádios de maturação. Lavras, 1995. 94 p. Dissertação (Mestrado em Ciência dos Alimentos) - Universidade Federal de Lavras.

PONTING, J. D.; JOSLYNG, M. A. Ascorbic acid oxidation and browing in apple tisSul extracts. Archives of Biochemistry, New York, v. 19, n. 1, p. 47-63, 1948.

PRESSEY, R.; AVANTS, J. K. Separation and characterization of endopolygalacturonase and exopolygalacturonase from peaches. Plant Physiology, Rockville, v. 52, n. 3, p. 252-256, Sept. 1973.

PRETE, C. E. C. Condutividade elétrica do exsudato de grãos de café (Coffea arabica L.) e sua relação com a qualidade de bebida. Piracicaba, 1992. 125 p. Tese (Doutorado em Fitotecnia) - Escola Superior de Agricultura Luiz de Queiroz.

QUESADA, J.; RUBIO, M.; GÓMEZ, D. Ozonation products of organosolvolytic extracts from vegetal materials. Journal of Agricultural and Food Chemistry, Washington, v. 46, n. 2, p. 692-697, Feb. 1998.

Radel, S. et al. Viability of yeast cells in well controlled propagating and standing ultrasonic plane waves. Ultrasonics, Amsterdam, v. 38, n. 1-8, p. 633-637, Mar. 2000.

RATNER, A.; GOREN, R.; MONSELINE, S. P. Activity of pectin esterase and cellulase in the abscission zone of citrus leaf explants. Plant Physiology, Washington, v. 44, n. 12, p. 1717-1723, Dec. 1969.

RIBEIRO, D. M. Qualidade do café descascado submetido a diferentes temperaturas, fluxos de ar e períodos de pré-secagem. Lavras, 2003. 86 p. Dissertação (Mestrado em Ciência dos Alimentos) Universidade Federal de Lavras.

RUNECKLES, V. C.; CHEVONE, B. I. Crop responses to ozone. In: Lefohn, A. (Ed.) Surface level ozone exposures and their effects of vegetation. Michigan: Lewis, Chelsea, 1992. p. 189-270.

Sarig, P. et al. Ozone for control of post-harvest decay of table grapes caused by Rhizopus stolonifer. Physiological and Molecular Plant Pathology, London, v. 48, n. 6, p. 403-415, June 1996. 
Schläfer, O. et al. Ultrasound stimulation of micro-organisms for enhanced biodegradation. Ultrasonics, Amsterdam, v. 40, n. 1-8, p. 25-29, May 2002.

SEYMOUR, I. J. et al. Ultrasound decontamination of minimally processed fruits and vegetables. International Journal of Food Science and Technology, Oxford, v. 37, n. 5, p. 547-557, June 2002.

SILVA, C. F. et al. Microbial diversity during maturation and natural processing of coffee cherries of Coffea arabica in Brazil. International Journal of Food Microbiology, Amsterdam, v. 60, n. 2-3, p. 251-260, Sept. 2000.

SILVA, N.; JUNQUEIRA, V. C. A.; SILVEIRA, N. F. A. Manual de métodos de análise microbiológica de alimentos. 2. ed. São Paulo: Varela, 2001. 317 p.

SIVETZ, M. Chemical properties of coffee. Coffee Processing Technology. Westport, 1963. v. 2, n. 379 p. 162-186.

SOUZA, S. M. C. O café (Coffea arabica L.) na região Sul de Minas Gerais: relação da qualidade com fatores ambientais, estruturais e tecnológicos. Lavras, 1996. 171 p. Tese (Doutorado em Fitotecnia) - Universidade Federal de Lavras.

SUÁREZ-QUIROZ, M. et al. Study of ochratoxin A-producing strains in coffee processing. International Journal of Food Science and Technology, Oxford, v. 39, n. 5, p. 501-507, May 2004.

SUSLOW, T. V. Ozone applications for postharvest disinfection of edible horticultural crops. Oakland: University of California, Division of Agriculture and Natural Resources, 2004. 8 p. Publication 8133.

TOCK, R. W. et al. Ruminant rations from mesquite biomass pretreated with water and ozone. Industrial \& Engineering Chemistry Product Research and Development, Washington, v 21, n. 1, p. 101-106, 1982.
VEIGA, S. M. O. M. Sanificação de carcaças de frango: processos alternativos. Lavras, 2003. 291 p. Tese (Doutorado em Ciência dos Alimentos) - Universidade Federal de Lavras.

VELANO, H. E. et al. Avaliação in vitro da atividade antibacteriana da água ozonizada frente ao Staphylococcus aureus. Pesquisa Odontológica Brasileira, São Paulo, v. 15, n. 1, p. 18-22, jan./ mar. 2001.

VILLELA, T. C. Qualidade do café despolpado, desmucilado, descascado e natural, durante o processo de secagem. Lavras, 2002. 69 p. Dissertação (Mestrado em Ciência dos Alimentos) Universidade Federal de Lavras.

Wang, H.; Feng, H.; Luo, Y. Microbial reduction and storage quality of fresh-cut cilantro washed with acidic electrolyzed water and aqueous ozone. Food Research International, Amsterdam, v. 37, n. 10, p. 949-956, 2004.

WIESE, C. B.; PELL, E. J. Oxidative modification of the cell wall in tomato plants exposed to ozone. Plant Physiology and Biochemistry, Paris, v. 41, n. 4, p. 375-382, Apr. 2003.

YAVICH, A. A. et al. Evaluation of biodegradability of NOM after ozonation. Water Research, Oxford, v. 38, n. 12, p. 2839-2846, Dec. 2004.

YOSEF, E. et al. Characterization of Some Cell Wall Components of Untreated and Ozone-Treated Cotton Stalks. Journal of Agricultural and Food Chemistry, Washington, v. 42, n. 1, p. 06-90, Jan. 1994.

ZANOTTI, P. D.; SOUSA NETO, E. M. História do café no Espírito Santo, no Brasil e no mundo. Vitória: Secretaria de Agricultura do Estado do Espírito Santo, 2005. 105 p. 